\title{
A Serological Comparison of Various Species of Mycoplasma by an Agar Gel Double-Diffusion Technique
}

\author{
By RUTH M. LEMCKE \\ The Lister Institute of Preventive Medicine, London, S.W. 1
}

(Received 12 August 1964)

\begin{abstract}
SUMMARY
Sixteen serological types of Mycoplasma previously distinguished by complement-fixation tests were compared by means of a gel precipitin (Ouchterlony) technique. Each of the sixteen gave a consistent pattern of three to seven precipitation lines with its homologous antiserum. Cross-reactions occurred between heterologous strains, especially with antisera produced with the aid of an adjuvant. Homologous reactions were complex and sufficiently distinctive for the technique to be used to identify unknown strains. Two of the sixteen types, Mycoplasma mycoides var. mycoides and $M$. mycoides var. capri, had certain antigenic components in common. The appearance of other cross-reactions suggested that the majority were due to the presence in different species of partly related rather than identical antigens.
\end{abstract}

\section{INTRODUCTION}

A previous communication (Lemcke, 1964a) reported the results of using a complement-fixation (CF) test to characterize mycoplasmas from a variety of sources. Among 82 strains, 17 serological types were distinguished, although two of these, Mycoplasma arthritidis and strain R 38, both from rats, were partly related. Although these serological types were easily distinguishable by complement-fixation tests, cross-reactions of the order of $1 / 16$ to $1 / 32$ of the homologous titres occurred between all of them. This phenomenon was also noted in complement-fixation tests by Card (1959) and Coriell, Fabrizio \& Wilson (1960). Non-specific reactions with certain constituents of the medium were responsible at least in part, but it was not clear whether certain antigenic components common to different species were also involved (Lemcke, 1964a). To clarify this point, an agar gel double-diffusion technique was used to examine the reactions of various Mycoplasma strains with homologous and heterologous antisera.

\section{METHODS}

Organisms. Details of the organisms used are given in Table 1. The sources of all the strains except BRA were described in earlier reports (Lemcke, 1964a, $b$ ). Strain BRA was freshly isolated from the rectum of a woman with vaginal cervicitis.

Media and growth conditions. The liquid medium used for cultures from which the gel diffusion antigens were prepared consisted of Hartley's digest broth (Oxoid) 
supplemented with: unheated horse serum $20 \%(\mathrm{v} / \mathrm{v})$; yeast extract (Oxoid), $0.5 \%(\mathrm{w} / \mathrm{v})$; deoxyribonucleic acid, $0.002 \%(\mathrm{w} / \mathrm{v})$; penicillin, $50 \mathrm{units} / \mathrm{ml}$. For the growth of cultures for immunizing rabbits, yeast extract was omitted and unheated pooled normal rabbit serum was substituted for horse serum. All strains were incubated at $37^{\circ}$, Mycoplasma salivarium, $\boldsymbol{M}$. orale and $\boldsymbol{M}$. fermentans anaerobically and the rest aerobically with continuous shaking.

Table 1. Mycoplasma strains

\begin{tabular}{|c|c|c|}
\hline Designation of strain & Source & Serological type or species \\
\hline $\begin{array}{l}\text { н34,* н 33, мJW, 4387 Р, н } 27 \\
\text { н 68, ВRA }\end{array}$ & Man (genital tract) & Mycoplasma hominis type 1 \\
\hline в 1, в $3, *$ в 5 & Man (mouth) & M. salivarium \\
\hline $837, * \mathbf{E}$ & Tissue culture & \\
\hline s, BM, $898 / 2$ & Man (throat) $\}$ & M. orale $\dagger$ \\
\hline G $2 *$ & Man (genital mucosa) & M. fermentans \\
\hline Navel* & Man (umbilicus) & Umbilical \\
\hline FH & $\begin{array}{l}\text { Man (primary atypical } \\
\text { pneumonia) }\end{array}$ & M. pneumoniae \\
\hline Campo (PG 27)*, or & Man (genital tract) & 'M. hominis type 2 ' \\
\hline Jasmin* & Rat (polyarthritis) & M. arthritidis \\
\hline R 38 & Rat (rhinitis) & $\begin{array}{l}\text { Partly related to } M . \\
\text { arthritidis }\end{array}$ \\
\hline M 1* & Mouse (lung) & M. pulmonis \\
\hline $\mathbf{K S A} *$ & Mouse ('rolling disease') & M. neurolyticum \\
\hline PG $11 *$ & Cattle (genital tract) & M. bovigenitalium \\
\hline Gladysdale* & $\begin{array}{l}\text { Cattle (contagious pleuro- } \\
\text { pneumonia) }\end{array}$ & \\
\hline G1/61* & $\left.\begin{array}{c}\text { Goat (contagious pleuro- } \\
\text { pneumonia) }\end{array}\right\}$ & M. mycoides var. mycoides \\
\hline pp. goat* & $\begin{array}{l}\text { Goat (contagious pleuro- } \\
\text { pneumonia) }\end{array}$ & M. mycoides var. capri \\
\hline Agalactia* & Goat (agalactia) & M. agalactiae \\
\hline Fowl* & $\begin{array}{l}\text { Chicken (upper respiratory } \\
\text { tract) }\end{array}$ & M. gallinarum \\
\hline A36* & Chicken (tracheal exudate) & Non-pathogenic avian \\
\hline $\mathbf{T}^{*}$ & Embryonated egg & $\begin{array}{l}\text { M. gallisepticum (Nelson's } \\
\text { coccobacilliform bodies) }\end{array}$ \\
\hline Laidlaw A* & Sewage & M. laidlawii \\
\hline
\end{tabular}

* Precipitating antisera available against these strains.

$\dagger$ Name assigned to new oral type (Dr D. Herderscheê, personal communication; TaylorRobinson, Canchola, Fox \& Chanock, 1964).

Preparation of antigens. Cultures were grown for 2-4 days since it was found that fewer precipitation lines were obtained with strain $\mathrm{H} 34$ when incubation was continued for 6-14 days. Organisms were harvested by centrifugation at $10,000 \mathrm{~g}$ for $30 \mathrm{~min}$. at $4^{\circ}$, washed twice in $0.85 \%(\mathrm{w} / \mathrm{v})$ saline and finally suspended in saline to a concentration 100 times that of the original culture. Although some precipitation lines were formed with suspensions of whole organisms, more were obtained with suspensions which had been cooled in ice and water and treated for $10 \mathrm{~min}$. with a Branson S-75 Sonifier (Branson Instruments Inc., Stamford, Connecticut, U.S.A.) at $20 \mathrm{kcyc}$. $/ \mathrm{sec}$. Suspensions in de-ionized water, which were frozen and thawed ten times in solid carbon dioxide + ethanol at $-\mathbf{2 5}^{\circ}$, gave precipitation patterns similar to those given by organisms disrupted ultrasonically. The freeze/thaw method was suitable for small quantities of culture. In most of the work reported below 
suspensions of organism from 250 or $500 \mathrm{ml}$. medium were disrupted ultrasonically. Suspensions were stored at $-25^{\circ}$ to $-30^{\circ}$ in volumes of $0.5-1.0 \mathrm{ml}$. Storage in large volumes was impracticable because some antigens deteriorated during the repeated thawing and freezing required for the removal of samples for test. Suspensions preserved at $4^{\circ}$ with the addition of thiomersalate (the procedure for storing complement fixation test antigens) gave fewer precipitation lines than those stored frozen. To detect non-specific reactions with the medium, a control 'antigen' consisting of the resuspended residue obtained by centrifugation of sterile broth was prepared.

Antisera. Most of the antisera used had been prepared for use in complementfixation tests (Lemcke, 1964a). They were selected for their ability to give precipitation lines with a suspension of homologous organism and were tested for reactivity with the medium and the control 'antigen'.

Antisera induced by antigen +Freund's adjuvant gave the best results in gel diffusion tests and new antisera were prepared by this method. The adjuvant consisted of a mixture of 9 parts Drakeol 6-VR (Pennsylvania Refining Co., Butler, Pa., U.S.A.) and 1 part Arlacel (Atlas Chemical Industries Inc., Wilmington, Del., U.S.A.). The organisms from $500 \mathrm{ml}$. of a 3- to 4-day culture were harvested by centrifugation, washed, resuspended in $2 \mathrm{ml}$. normal saline and homogenized with an equal volume of adjuvant. Rabbits were inoculated subcutaneously in the flank. Those receiving samples of strains в 3, G 2 and Campo were given one injection, those receiving strains 837 and Navel two injections separated by an interval of 3 weeks. Three weeks after the last subcutaneous inoculation, all the rabbits were given a course of six intravenous injections of the appropriate organism suspended in saline. The best antisera were obtained 5-7 days after the last intravenous injection.

Double-diffusion tests. The medium and pattern of the reservoirs used were those described by Lemcke (1964a). Precipitation was allowed to take place at room temperature; at $4^{\circ}$ fewer lines developed and at $30-37^{\circ}$ the lines became very diffuse. Optimal development occurred between 2 and 5 days, depending on the antiserum.

\section{RESULTS}

Of the stock antisera tested for ability to give precipitation lines with homologous antigen preparations, only those against Mycoplasma pneumoniae and strain $\mathrm{R} 38$ did not react. Thus, precipitating antisera were available against 15 of the 17 serological types previously described (Lemcke, 1964a) and against $M$. gallinarum, another 'avian' species which proved to be serologically distinct by the complement-fixation test (Table 1). Of these 16 type antisera, 14 gave no sign of precipitation with the medium or control 'antigen'. The remaining two, an antiserum against strain KSA (Mycoplasma neurolyticum) and one against strain Gladysdale ( $\boldsymbol{M}$. mycoides var. mycoides) gave diffuse zones of precipitation with both the medium and the control 'antigen'. With both, the reaction was eliminated by absorption of the sera with an equal volume of medium. The absorbed sera, even though diluted $1 / 2$ by this procedure, gave several clear precipitation lines with the homologous antigen; only the rather diffuse non-specific band disappeared. In the case of strain KSA, the absorbed antiserum did not react with suspensions of any other strains. 
Adjuvant-induced antisera gave more precipitation lines with their homologous antigens than did antisera produced by the intravenous inoculation of saline suspensions (Table 2).

The results of cross-testing suspensions with 16 antisera against strains representing different serological types are shown in Table 3. When two antisera were available against any one strain, as was the case for strains $\mathrm{H34}, \mathrm{B3}, 837, \mathrm{G} 2$, Navel and Campo, the results obtained with the adjuvant-induced serum are given. Although heterologous cross-reactions were frequent, the homologous reaction in each case was always more complex and characteristic of the particular strain. To make sure that none of the cross-reactions represented non-specific reactions, all

Table 2. Comparison of antisera produced by suspensions of mycoplasmas, with and without adjuvants

\begin{tabular}{|c|c|c|c|c|}
\hline \multirow[b]{2}{*}{ Mycoplasma strain } & \multicolumn{2}{|c|}{$\begin{array}{l}\text { No. of precipitation lines } \\
\text { with homologous suspensions }\end{array}$} & \multicolumn{2}{|c|}{$\begin{array}{c}\text { Cross-reactions with } \\
\text { heterologous suspensions }\end{array}$} \\
\hline & $\begin{array}{c}\text { With } \\
\text { adjuvant }\end{array}$ & $\begin{array}{c}\text { No } \\
\text { adjuvant }\end{array}$ & $\begin{array}{l}\text { With } \\
\text { adjuvant }\end{array}$ & $\overbrace{\text { adjuvant }}^{\text {No }}$ \\
\hline H 34 & 6 & $1-2$ & + & - \\
\hline B 3 & 4-5 & $\mathbf{2}$ & + & - \\
\hline 837 & $6-7$ & 2 & + & - \\
\hline G2 & $5-7$ & $\mathbf{2}$ & + & - \\
\hline Navel & 3 & 1 & - & - \\
\hline Campo (PG 27) & $5-6$ & 2 & + & + \\
\hline
\end{tabular}

cross-reacting sera were tested against concentrations of the complete medium up to twenty-five times and against two-fold dilutions down to 1/4096 of the complete medium, Hartley's digest broth, undiluted horse serum, yeast extract $(10 \%, \mathrm{w} / \mathrm{v})$, and deoxyribonucleic acid $(0 \cdot 2 \%, w / v)$. No precipitation lines were detected in any of these tests.

There was a substantial degree of cross-reaction between the strains н34 (Mycoplasma hominis type 1), B3 (M. salivarium), 837 (M. orale), G2 (M. fermentans) and Navel, which represented five different serological types of human origin (Table 3). Of these, only antiserum to strain Navel was entirely monospecific, despite the use of adjuvant in its preparation; suspensions of this strain did, however, react with antisera to the other serotypes of human origin. Table 3 also shows extensive cross-reactions between the five strains of human origin and Campo, a strain of the so-called 'Mycoplasma hominis type 2'. Although strain Campo and another 'type 2' strain, o7, were isolated from the human genital tract, complement-fixation tests have shown them to be indistinguishable from strains of $M$. arthritidis associated with polyarthritis in rats (Lemcke \& Csonka, 1962; Lemcke, 1964a). Gel diffusion tests confirmed that strains Campo and o7 were very closely related to $\boldsymbol{M}$. arthritidis strain Jasmin. With antiserum to strain Campo, strain Jasmin shared at least four precipitation lines with strain Campo, but lacked another line (A) given by the latter (Fig. 1a). With antiserum to strain Jasmin, strains Campo, of and Jasmin shared three lines of precipitation (Fig. 1b). In addition strains Campo and Jasmin had a fourth line, nearest the antigen well, which formed a spur at the point of junction $(B)$ and was therefore not quite identical in the two organisms; this component was apparently missing from 07. 
Table 3. Number of gel precipitation lines obtained in homologous and heterologous reactions with Mycoplasma strains

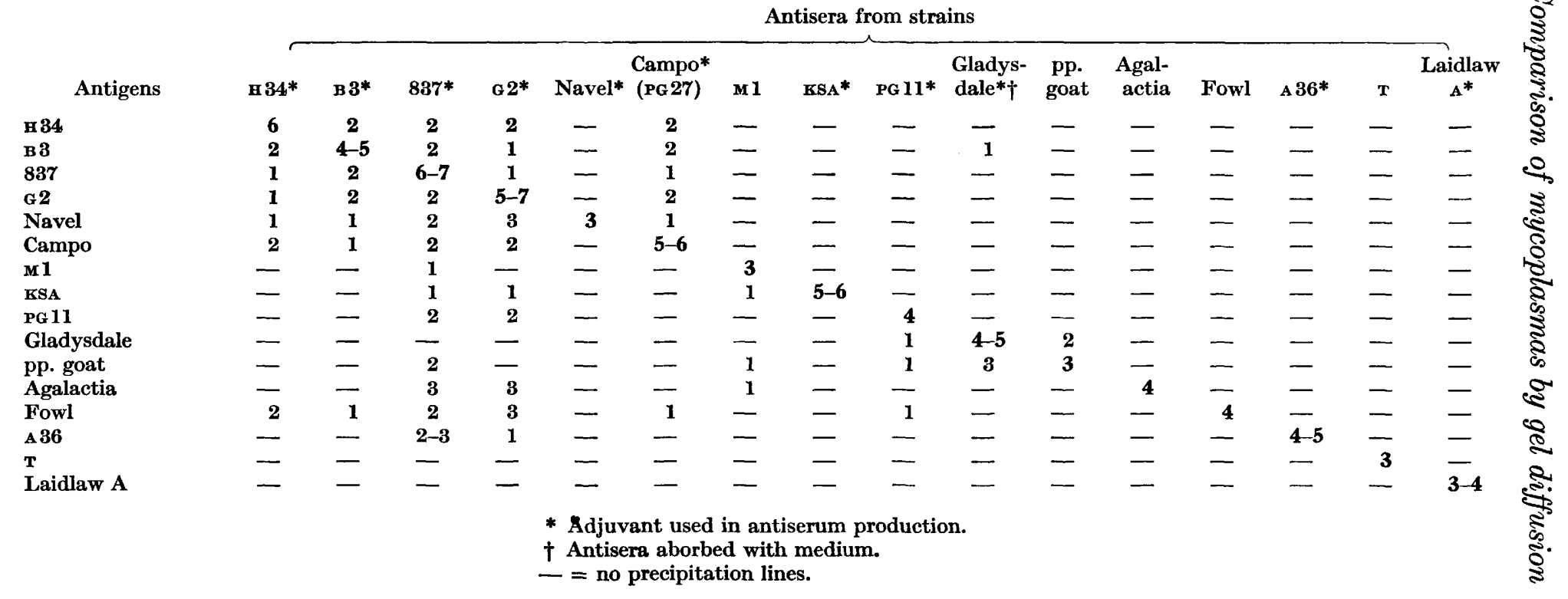


The technique thus revealed a slight difference, not apparent from the results of complement-fixation tests, between the 'type 2 ' strains from man and $M$. arthritidis from a rat. Nevertheless, since strains from both sources shared the majority of their antigens, there seems to be no justification for regarding ' $M$. hominis type 2 ' as a species distinct from $M$. arthritidis (Lemcke, 1964a).

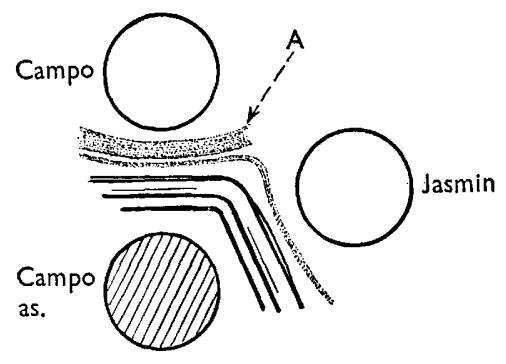

(a)

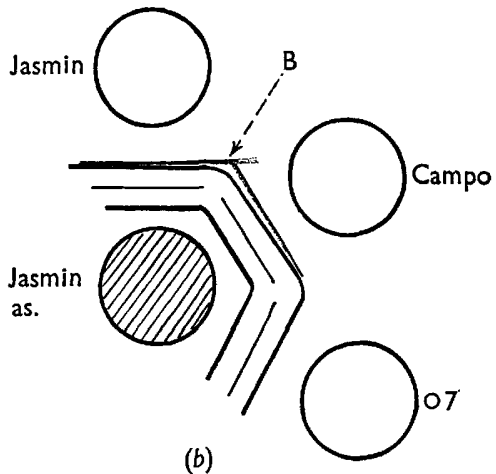

(b)

Fig. 1. Agar gel precipitin reactions of (a) antiserum to 'Mycoplasma hominis type 2' strain Campo with homologous strain and $M$. arthritidis strain Jasmin (A, extra band formed by homologous strain), and (b) antiserum to $M$. arthritidis strain Jasmin with homologous strain and ' $M$. hominis type 2' strains Campo and o7 (B, partial intersection of lines from strains Jasmin and Campo). as. = antiserum well.

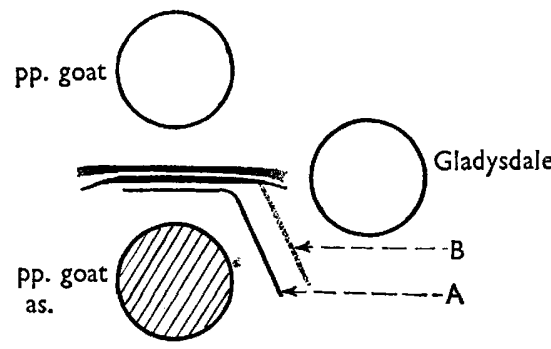

(a)

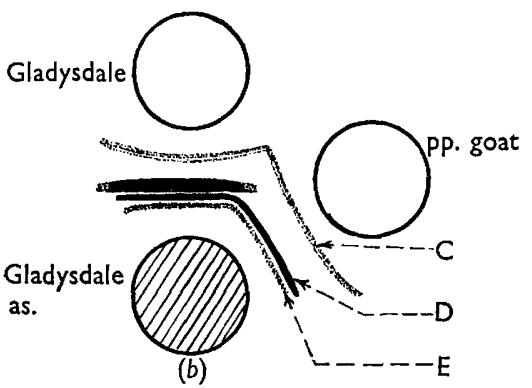

(b)

Fig. 2. Agar gel precipitin reactions of (a) antiserum to Mycoplasma mycoides var. capri strain pp. goat with homologous strain and M. mycoides var. mycoides strain Gladysdale (A, line common to both strains; B, line partly intersecting with one of homologous lines), and $(b)$ antiserum to $M$. mycoides var. mycoides strain Gladysdale with homologous strain and M. mycoides var. capri strain pp. goat (C, D, E, lines common to both strains). as. = antiserum well.

With regard to the nature of the cross-reactions between the sixteen serological types, two of them, Mycoplasma mycoides var. mycoides from contagious bovine pleuropneumonia and $M$. mycoides var. capri from contagious pleuropneumonia in a goat, clearly had common antigens. With antiserum to $M$. mycoides var. capri strain pp. goat, M. mycoides var. mycoides strain Gladysdale gave one precipitation line which fused completely with one produced by the homologous strain (Fig. 2a, line A). A second line partially intersected with one of the other two homologous lines giving spur formation (Fig. $2 a$, line B). This suggested the presence of one identical and one partly related component in the two organisms. The reciprocal 
test with antiserum to $\boldsymbol{M}$. mycoides var. mycoides strain Gladysdale (Fig. $2 b$ ), showed that three of the precipitation lines $(\mathrm{C}, \mathrm{D}, \mathrm{E})$ formed by 'mycoides' and 'capri' were identical. Tests with an antiserum to $M$. mycoides var. mycoides strain $\mathrm{G} 1 / 61$ (a strain from goat pleuropneumonia but indistinguishable from strain Gladysdale) showed that 'mycoides' and 'capri' had one antigenic component in common and one partly related. The rather more complex picture obtained with antiserum to strain Gladysdale was probably due to the use of adjuvant in its production; strains pp. goat and G1/61 antisera were prepared without adjuvant. 'Mycoides' and 'capri' also had an identical line in their cross-reaction with antiserum to $M$. bovigenitalium, suggesting an antigenic component common to both.

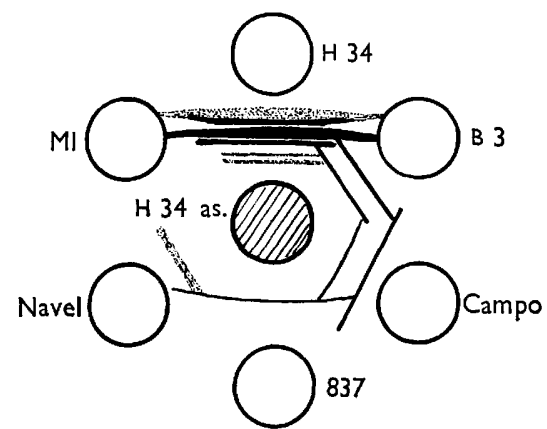

(a)

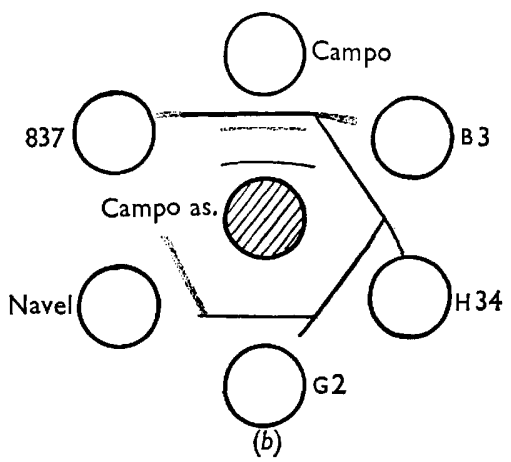

(b)

Fig. 3. Agar gel precipitin reactions of (a) antiserum to Mycoplasma hominis type 1 strain $\mathbf{H 3 4}$, with homologous strain, $M$. salivarium strain $B 3$, ' $M$. hominis type 2 ' strain Campo, M. orale strain 837, M. pulmonis strain M 1 and strain Navel, and $(b)$ antiserum, obtained after one subcutaneous inoculation, to ' $\boldsymbol{M}$. hominis type 2' strain Campo with homologous strain, $M$. salivarium strain в 3, M. hominis type 1 strain н 34, M. fermentans strain $\mathrm{G} 2, \boldsymbol{M}$. orale strain 837 and strain Navel. as. = antiserum well.

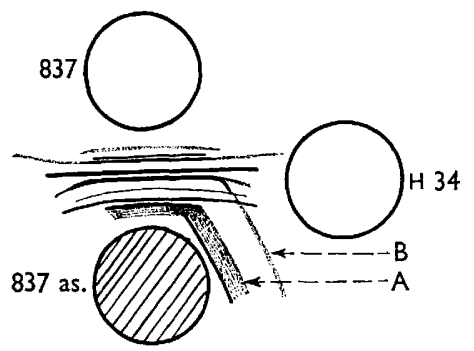

Fig. 4. Agar gel precipitin reactions of antiserum to Mycoplasma orale strain 837 with homologous strain and $M$. hominis type 1 strain $\mathrm{H}$ 34 (A, diffuse band apparently fusing with one of homologous lines; B, line partly intersecting with one of homologous lines). as. = antiserum well.

In most of the other cross-reactions spur formation occurred where the heterologous precipitation lines joined one or other of the homologous lines (Fig. $3 a, b$ and Fig. 4, line B). In some cases, the complexity of the homologous pattern tended to obscure the junction of homologous and heterologous lines. Nevertheless, reactions with less complex sera obtained after a single subcutaneous injection suggested that spur formation did indeed occur (Fig. 3b). Both Figs. $3 a$ and $b$ 
illustrate reactions with several different heterologous strains. Spur formation occurred not only between the homologous and the adjacent heterologous systems, but also between different heterologous strains.

Besides the partly related antigens indicated by spur formation, a few strains may have identical antigens in common. With Mycoplasma orale strain 837 antiserum, $\boldsymbol{M}$. hominis type 1, M. salivarium, $\boldsymbol{M}$. fermentans, Navel, ' $\boldsymbol{M}$. hominis type 2' and $\boldsymbol{M}$. gallinarum all showed a rather diffuse precipitation band which apparently fused with the homologous line nearest the antiserum well. The width and diffuseness of the bands may however give a false appearance of fusion (Fig. 4, line A). Similar reactions were observed between $\boldsymbol{M}$. salivarium strain в 3 antiserum and $\boldsymbol{M}$. orale, and between $\boldsymbol{M}$. fermentans strain $\mathrm{G} 2$ antiserum, and $\boldsymbol{M}$. orale and $\boldsymbol{M}$. gallinarum.

The technique was also used to compare strains which were indistinguishable by the complement-fixation test. Thus, with any one antiserum to Mycoplasma hominis type 1 , strains from a post-operation wound infection ( $\mathrm{H} 34)$, non-gonococcal urethritis (н 33, мJw, 4387 Р), Reiter's disease (н 27), Bartholin's abscess (н 68) and the rectum (BRA) gave similar reactions. No difference was detectable between the freshly isolated strain BRA and the others, which had been maintained in the laboratory for some time. The only differences noted between strains were in the intensity of certain of the weaker precipitation lines. Such differences were probably due to the deterioration during storage of the more labile antigenic components, since the same lines were found to be missing when suspensions of strain H 34, were stored at $4^{\circ}$ with thiomersalate and when cultures to be used as antigens were incubated for 6-14 days instead of 2-4 days.

Apart from differences in intensity, the precipitation reactions of these seven human genital strains were indistinguishable and the results thus confirm those obtained by the complement-fixation test (Lemcke, 1964a). Some earlier observations (Nicol \& Edward, 1953; Card, 1959; Oates, Whittington \& Wilkinson, 1959; Lemcke \& Csonka, 1962 and Taylor-Robinson, Somerson, Turner \& Chanock, 1963) suggested that there might be slight antigenic differences between strains of Mycoplasma hominis type 1. There was, however, no evidence from the strains examined here that some possessed antigenic components not present in others.

Three strains from the human mouth (в 1, в 3, в 5; Card, 1959) appeared identical when tested with antiserum to strain $\mathrm{B} 3$, just as in complement-fixation tests.

The similarity of certain tissue culture contaminants isolated by Hayflick to a new oral type (Herderscheê, Ruys \& van Rhijn, 1963) was reported previously (Lemcke, 1964b). This type has been named Mycoplasma orale (Dr D. Herderscheê, personal communication; Taylor-Robinson, Canchola, Fox \& Chanock, 1964). The precipitation patterns of the strains from tissue cultures (strains 837, E) and from the human throat (strains s, BM, 898/2) were closely similar, the only difference being in the intensity of the precipitation band nearest the antigen wells. This may have been due to the better preservation of a labile antigenic component in some suspensions than in others or it may have reflected differences in the amount of a particular antigen present in different strains. 


\section{DISCUSSION}

It is clear that in many of the Mycoplasma species examined here there was a complexity of antigenic components not revealed in previous immunodiffusion studies (e.g. Villemot \& Provost, 1959; Taylor-Robinson et al. 1963). Clearly, much depends on the quality of the antiserum used; some of the best antisera were produced with the aid of adjuvant in the primary subcutaneous inoculation of rabbits, followed by a secondary course of intravenous injections. The disrupted cell suspensions need to be concentrated, and the contained antigens (some of which are labile) preserved from deterioration. Homologous reactions were always clearly distinguishable from the cross-reactions. The gel diffusion technique therefore constitutes a relatively simple method of identification, provided the appropriate antisera are available. It has been successfully used in this laboratory for identifying mycoplasmas from human genital infections.

However, the results are probably of greater significance as a basis for further work on the separation and purification of the various antigenic components. Immunochemical studies of this kind have so far been concerned mainly with the contagious bovine pleuropneumonia organism $M$. mycoides var. mycoides (Dafaalla, 1957 ; Yoshida, 1961; Plackett, Buttery \& Cottew, 1963). Similar work on species of human origin would be of value in improving serological methods for diagnosing mycoplasma infections in man.

There was no evidence from the present work, after exhaustive tests, that the cross-reactions observed between different species in gel diffusion tests were nonspecific. Cross-reactions in the complement-fixation test were thought to be associated, at least in part, with the broth medium (tryptic digest of horse meat) used to grow cultures for both the complement-fixation test antigen and for immunizing rabbits (Lemcke, 1964a). In fact, a different broth medium (Hartley's digest of beef heart muscle) was used to grow the suspensions used in gel diffusion tests. It seems clear from these tests that cross-reactions between species of $M y c o-$ plasma are due to specific antigenic components. More cross-reactions between species would probably have been detected if potent sera against each strain had been available.

The cross-reacting antigenic components were sometimes identical. Mycoplasma mycoides var. mycoides and capri probably possessed three antigens in common. Because they can be distinguished serologically, the author previously thought that there was little justification for regarding the goat pleuropneumonia organism as a variant of the bovine pleuropneumonia organism and for naming them both as varieties of $M$. mycoides (Lemcke, 1964a). However, the precipitation patterns show that these two organisms are more closely related than any of the other serological types examined. Most of the other cross-reactions appeared to be due to partly related rather than identical antigens. There was no evidence of the widespread distribution of the same antigens among very diverse species of Mycoplasma, as suggested by Villemot $\&$ Provost (1959). Nevertheless, the use of complex mixtures of antigens which comprise the disrupted suspensions makes it difficult to determine the exact relationship between some of the cross-reacting components. These need further study, with cross-absorbed antisera and with, if possible, the separate individual components. 


\section{REFERENCES}

CARD, D. H. (1959). PPLO of human genital origin. Serological classification of strains and antibody distribution in man. Br. J. vener. Dis. 35, 27.

Coriell, L. L., Fabrizio, D. P. \& Wilson, S. R. (1960). Comparison of PPLO strains from tissue cultures by complement fixation. Ann. N.Y. Acad. Sci. 79, 574.

DafaAma, E. N. (1957). A study of the antigenic structure of the contagious bovine pleuropneumonia organism. Bull. epizoot. Dis. Afr. 5, 135.

Herderschê̂, D., Ruys, A. C. \& van RhiJn, G. R. (1963). A new oral Mycoplasma isolated from the tonsils of two patients suffering from scarlatina. Antonie van Leeuwenhoek, 29, 157.

LEMCKe, R. M. (1964a). The serological differentiation of Mycoplasma strains (pleuropneumonia-like organisms) from various sources. J. Hyg., Camb. 62, 199.

LEMcke, R. M. (1964b). The relationship of a type of Mycoplasma isolated from tissue cultures to a new human oral Mycoplasma. J. Hyg., Camb. 62, 351.

Lemcke, R. M. \& Csonka, G. W. (1962). Antibodies against pleuropneumonia-like organisms in patients with salpingitis. Br. J. vener. Dis. 38, 212.

Nicol, C. S. \& EDward, D. G. ff. (1953). Role of organisms of the pleuropneumonia group in human genital infections. Br. J. vener. Dis. 29, 141.

OAtes, J. K., Whittington, M. J. \& Wilkinson, A. E. (1959). A note on the results of cultural and serological tests for pleuropneumonia-like organisms in Reiter's disease. Br. J. vener. Dis. 35, 27.

Plackett, P., Buttery, S. H. \& Cottew, G. S. (1963). Carbohydrates of some Mycoplasma strains. Recent Progress in Microbiology, 8, 535. Toronto: University of Toronto Press.

Taylor-Robinson, D., Canchola, J., Fox, H. \& Chanock, R. M. (1964). A newly identified oral Mycoplasma (M. orale) and its relationship to other human mycoplasmas. $\mathrm{Am}$. J. Hyg. 80, 135.

Taylor-Robinson, D., Somerson, N. L. Turner, H. C. \& Chanock, R. M. (1963). Serological relationships among human mycoplasmas as shown by complement fixation and gel diffusion. $J$, Bact. 85, 1261.

Villemot, J. M. \& Provost, A. (1959). Recherches immunologiques sur la peripneumonie. V. Relations antigeniques entre Mycoplasma mycoides var. mycoides, $M$. mycoides var. capri et d'autres micro-organismes du genre Mycoplasma (souches génitales bovines et humaines). Rev. Elev. 12, 251.

Yoshida, T. (1961). Antigenicity of cell components of antigenic variants of contagious bovine pleuropneumonia organisms in serological tests. Nat. Inst. Anim. Hlth Quart. (Tokyo), 1, 199. 